\title{
PARENTAL INVESTMENT AND CHILD HEALTH IN A YANOMAMÖ VILLAGE SUFFERING SHORT-TERM FOOD STRESS
}

\author{
EDWARD H. HAGEN*, RAYMOND B. HAMESt, NATHAN M. CRAIG*, \\ MATTHEW T. LAUER* AND MICHAEL E. PRICE*
}

*D epartment of A nthropology, U niversity of California, Santa Barbara, CA 93106 and †D epartment of Anthropology, U niversity of N ebraska-L incoln, USA

\begin{abstract}
Summary. The $1998 \mathrm{EI} N$ iño significantly reduced garden productivity in the U pper Orinoco region in Venezuela. Consequently, parents were forced to allocate food carefully to their children. N utrition data collected from village children combined with genealogical data allowed the determination of which children suffered most, and whether the patterns of food distribution accorded with predictions from parental investment theory. For boys, three social variables accounted for over $70 \%$ of the variance in subcutaneous fat after controlling for age: number of siblings, age of the mother's youngest child, and whether the mother was the senior or junior co-wife, or was married monogamously. These results accord well with parental investment theory. Parents experiencing food stress faced a trade-off between quantity and quality, and between investing in younger versus older offspring. In addition, boys with access to more paternal investment (i.e. no stepmother) were better nourished. These variables did not account for any of the variance in female nutrition. Girls' nutrition was associated with the size of their patrilineage and the number of non-relatives in the village, suggesting that lineage politics may have played a role. A $n$ apparent lack of relationship between orphan status and nutrition is also interesting, given that orphans suffered high rates of skin flea infections. The large number of orphans being cared for by only two grandparents suggests that grooming time may have been the resource in short supply.
\end{abstract}

\section{Introduction}

A number of evolution-minded researchers have argued that when food, time or other resources are constrained, parents will invest these resources differently in different offspring depending on the offspring's sex, age, health and relatedness to the parent (Clutton-Brock, 1991; D aly \& Wilson, 1984, 1988; H rdy, 1992; Trivers, 1972, 1974). 
This argument forms an important facet of what is usually referred to as parental investment (PI) theory, a subset of life history theory.

To test the hypothesis that parents experiencing resource constraints will invest differentially in offspring, and that the patterns of investment accord with PI theory, a number of health, nutrition and social variables were measured for all children between the ages of 5 and 15 living in a $Y$ anomamö village on the $U$ pper Orinoco River in southern $V$ enezuela. The $\mathrm{Y}$ anomamö are $\mathrm{N}$ ative American swidden horticulturists living in the tropical forests of southern Venezuela and northern Brazil. They number approximately $15-20,000$, and live in 200-250 widely scattered villages (Chagnon, 1992). The study site, with 148 inhabitants, was a moderately large village. D ata were collected during the summer of 1998.

A ccording to local inhabitants, garden productivity in the U pper Orinoco region was significantly below normal at the time of the study, a fact that can be attributed to the EI Niño weather conditions in 1997-1998. Colleagues in the region conducted several aerial surveys, and provided convincing photographic evidence that many local gardens had been damaged by heavy flooding. During the field season, there were numerous reports of food shortages in the $Y$ anomamö and $Y e^{\prime} k w a n a$ communities along the river. Inhabitants of the study site reported that they were no longer suffering shortages, although they had been a few months earlier. D uring that time, village leaders travelled to local missions and military bases in search of food, and one leader with a government salary purchased food for the village. Informants also said that communities up-river were still having problems, although nobody was actually starving. Anthropometric data collected from the village children indicated that they may have suffered, and perhaps were still suffering nutritional stress. These data, in concert with genealogical information collected from village inhabitants, allowed determination of which children suffered most from the food shortages, and whether the patterns of food distribution accord with theoretical predictions from PI theory.

\section{Parental investment theory}

Parental investment (PI) theory is an aspect of life history theory (e.g. A lexander, 1974; Bateman, 1948; Clutton-Brock, 1991; H aig, 1990; H rdy, 1977, 1979; K elly \& K ennedy, 1993; Lessells, 1991; M ock \& Parker, 1986; Stearns, 1992; Trivers, 1972, 1974, 1985; Trivers \& Willard, 1973). It has provided the evolutionary framework for nearly 20 years of research into parental investment in offspring for both humans (Betzig, Borgerhoff M ulder \& Turke, 1988; Blurton Jones, 1989; Chisholm, 1993; Daly \& Wilson, 1984, 1988; Dickemann, 1979, 1981; D raper \& H arpending, 1982; Hagen, 1996, 1999; Haig, 1993; Hames, 1996; Hill \& Kaplan, 1988; Hrdy, 1992; Lampert \& F riedman, 1992; Voland, 1984), and other species (the literature is huge; see Clutton-Brock (1991), R off (1992) and Stearns (1992) for recent syntheses).

To briefly review, life history theory posits that the ancestors of any species must have solved the problems of survival, growth and development on the one hand, and reproduction on the other. Because each of these problems is characterized by unique difficulties, and because time, energy and resources are finite, organisms must optimally allocate these commodities between somatic effort (growth and development, and maintenance of the organism) and reproductive effort (producing offspring 
who survive to reproductive age, or providing benefits to close relatives who themselves produce offspring).

R eproductive effort, in turn, should be optimally allocated between mating effort (locating and acquiring a mate), and parenting effort (e.g. gestation and raising of offspring) - what here is termed parental investment in order to be consistent with existing literature (see Clutton-Brock, 1991, p. 8, for a discussion of terminology). Parental investment theory focuses on those aspects of an organism's life history that are specifically involved with producing and raising offspring.

Life history theorists assume that the physiological and behavioural characteristics of organisms represent an approximate solution to the problem of optimizing the allocation of time, energy and resources between somatic, mating and parenting effort. The particular solution will depend on the organism's environmental niche as well as its evolutionary history. In general, effort allocated to reproduction will decrease an organism's ability to survive, grow and develop. Conversely, effort allocated to survival, growth and development will decrease reproduction. Similarly, effort allocated to finding a mate will decrease an organism's ability to invest in offspring, whereas effort invested in offspring will reduce an organism's ability to acquire a mate. If parental investment can only occur at the expense of somatic or mating effort, then parents need to decide, based on cues from the current environment, whether it is more advantageous to invest finite resources in offspring and other kin, mates or themselves. Further, if investment in one offspring decreases the investment available to other offspring, parents should allocate resources in a manner that, in ancestral environments, would have increased their own inclusive fitness. A number of straightforward predictions follow from these assumptions, and it was possible to test several with the data available.

\section{P revious research and study predictions}

A number of studies have examined differential parental investment in humans. Proxy measures of investment in offspring or the lack thereof include rates of infanticide, homicide and abuse (e.g. D aly \& Wilson, 1984, 1988), emotional attitudes towards as well as interactions with infants (e.g. Hagen, 1996, 1999; M ann, 1992), patterns of wealth inheritance, including payments of bridewealth and dowry (e.g. Borgerhoff M ulder, 1995; D ickemann, 1981; M ace, 1998), direct care (e.g. Betzig \& Turke, 1986; H ewlett, 1991), educational investment (e.g. Borgerhoff M ulder, 1998) and birth weight and lactation (e.g. Gaulin \& Robbins, 1991; M argulis, A Itmann \& Ober, 1993; San Jose, Braza \& Casanova, 1997).

This study included two proxy measures of parental investment: (1) the triceps skinfold thicknesses of all children aged 5-15 years, an index of nutrition; and (2) the degree of ectoparasite load suffered by these same children, an index of health (more on these measures below). The dataset also included information on garden size and soil quality, the owner of the garden and a complete genealogy of the village. Predictions were derived from a straightforward application of PI theory to this dataset.

A foundational assumption of $\mathrm{PI}$ theory is that offspring production is constrained by resources: large families require more food. Because plantain and manioc gardens 
were the major source of calories at the study site, large family sizes should be associated with large gardens. Chayanov was one of the first to consider the relationship between household size and household production, claiming, in brief, that there should be a positive relationship between the number of consumers and household production. Tests of Chayanov's theories have been many, and have generally found that the relationship between number of consumers and household productivity is positive, with correlation coefficients ranging from approximately 0.30 to 0.90 (see Chibnik, 1984, for a cross-cultural examination of Chayanov's theories; see also D urrenberger, 1984). These results accord well with PI theory, although they are derived from a different theoretical framework. The data allowed the examination of the correlation between family size and garden productivity, which is also predicted to be positive.

A nother fundamental prediction of parental investment theory is that parents will experience a fitness trade-off between fewer, 'high quality' offspring, and more 'low quality' offspring (Lack, 1947). The more children parents choose to have, the less they can invest in each. The optimal number of offspring will depend, in part, on the non-linear relationship between investment and viability. Blurton Jones (1986) tested this hypothesis with the !K ung, and found that the birth interval that led to the highest number of surviving offspring was also the most common birth interval in the population (although this result was later questioned: see Harpending (1994), and Blurton Jones' reply (1994)).

In contrast, a series of careful, long-term studies of the A che of Paraguay by $\mathrm{H}$ ill \& Hurtado (1996) failed to detect the expected trade-off between offspring quantity and quality. High reproductive rates by adults had no negative impact on their subsequent survival or fertility, nor did they seem to affect the fertility of their children (cf. Pennington \& Harpending, 1988). Hill and Hurtado found no support for the notion that $A$ che parents who raise many children produce lower quality children than those parents who limit their reproductive output. They speculate that their failure to detect the expected reproductive trade-offs may stem from an inadequate assessment of collateral kin effects. $\mathrm{H}$ igh-fertility adults may be a resource drain on their relatives, who consequently have reduced fertility. A Iternatively, reproductive trade-offs may only be apparent during times of stress, periods that were excluded from their analyses. The current study was able to examine the quantity/ quality trade-off hypothesis during a period of resource stress, and is thus a test of one of Hill and Hurtado's alternative hypotheses.

There is a growing theoretical and empirical literature on the health and reproductive correlates of polygyny in both humans and other animals. The polygyny-threshold model (Orians, 1969; Verner \& Willson, 1966) was an early and influential model first developed for birds, and later extended to humans (e.g. Borgerhoff M ulder, 1988; J osephson, 1993; cf. Becker, 1981). B riefly, this model posits that because polygyny is always reproductively advantageous for males, its presence or absence will depend on whether or not it is advantageous for females. If there are marked differences in male mate quality (e.g. the levels of resources controlled by the male), females may benefit by mating with the highest quality males, even if these males are already mated and allocating resources to other females. On this view, mothers and their children in polygynous households will be dividing a larger pie, and 
should therefore not suffer nutritional or other deficits relative to mothers and children in monogamous households.

By contrast, later models view polygyny as the consequence of male efforts to control females, to the detriment of both females and unmated males (e.g. Chisolm \& Burbank, 1991; Davies, 1989; D ownhower \& Armitage, 1971; Irons, 1983). The negative effects for females in these models are thought to result from a dilution of paternal investment, but may also be due to costs imposed by co-wives (see, e.g., Strassmann, 1997). These later models are gaining increasing empirical support. For example, Strassmann (1997) found that polygyny among the Dogon (W est A frican agriculturists) was correlated with high rates of child mortality: the odds of death for children in groups with high rates of polygyny were 7-11 times higher than for children in monogamous groups. Sellen (1999) similarly found that, among the D otoga (a group of East A frican pastoralists), the children of first and second wives had poorer growth and nutrition than did children of other mothers. There have also been a number of studies examining the relationship between polygyny and fertility, but no clear picture has emerged (see Wood, 1994, for a review).

A key difference between these models is the extent to which mothers and fathers - or, more precisely, their children - either benefit or suffer in polygynous matings. The data collected in this study allowed the testing of whether polygyny accounted for any variance in child nutrition and health under conditions of short-term food stress, and further, if it did, whether the 'costs' or 'benefits' of polygyny applied differently to mothers and fathers.

A trade-off also exists between investing in older versus younger offspring. Older children have higher reproductive value due to their demonstrable success in survival, growth and development, but are likely to survive even if investment is reduced. Y ounger children and newborns, on the other hand, have lower reproductive value due to high rates of mortality, but have little chance of survival without continual care and attention. A gain, the optimal solution will depend, in part, on the precise (non-linear) relationship between allocation and fitness returns. D uring limited periods of resource stress, parents may favour investing in infants since older children can buffer shortterm deficits in parental care. Conversely, longer periods of stress may incline parents to invest in older children since infants are unlikely to survive in any case. Daly \& W ilson $(1984,1988)$ tested this latter proposition by looking at rates of child abuse and homicide committed by parents relative to the age of the child. They found that infants (who have lower intrinsic reproductive value) were far more likely than older children to be killed by parents, a pattern that differed markedly from child homicides committed by non-parents, even after accounting for rates of child exposure to parents versus non-parents. Because the current study was conducted during a period of short-term resource stress, it was possible to test whether parents invested in younger children at the expense of their older children under these conditions.

Evolutionary theory predicts that parents will preferentially invest in their own biological offspring. Parents receive the greatest inclusive fitness benefits if they direct their investment towards their offspring as opposed to step-offspring, the children of siblings, the children of co-wives, or the children of other relatives and friends. This prediction has found surprisingly strong support in some studies. For example, Daly $\&$ Wilson $(1984,1988)$ found that living with a step-parent is the most powerful risk 
factor for child abuse that has yet been identified, and, based on data collected in 1976, it increased an A merican child's risk of being killed a hundred-fold. Although there were few step-parents at the field site, there were a relatively large number of orphans, so it was possible to test whether orphan status accounted for any variance in child health or nutrition.

Parents may realize higher fitness payoffs by investing in females instead of males, or visa versa (Trivers \& Willard, 1973). In many species, including humans, male reproduction is both more variable in outcome than for females, and often incurs more costs from intrasexual competition for mates. $M$ ales with access to considerable resources can attract multiple mates and potentially sire hundreds of offspring, whereas males with few resources may be unable to attract a mate, and consequently sire no offspring. Females, on the other hand, are limited to a dozen or so offspring, but are very unlikely to go childless - sperm is cheap. Parents with fewer resources may take the safer bet and invest in daughters, while parents with substantial resources may choose to invest more in sons.

To give but a few examples of the many studies examining sex-biased parenting in humans, Borgerhoff Mulder (1998) found that poor K ipsigis families showed a greater concern for their daughters' education than did rich families. Gaulin \& Robbins (1991) measured maternal investment (e.g. birth weight, interbirth interval and lactational commitment) among a sample of approximately 900 US mothers. $M$ aternal condition was assessed by income and by the presence or absence of a co-resident adult male. Some measures of investment (five of fourteen statistical tests) showed marked and significant sex-by-condition interactions of the type and in the direction predicted by Trivers and Willard and none showed significant effects in the opposite direction. F or reviews of the large but discrepant literature on sex-ratio see, for example, James (1987), Sieff (1990) and Cronk (1991). U nfortunately, the design of this study provided little opportunity to identify sex-biased investment. The anthropometric measures of nutrition have distributions that inherently differ by sex, there was no measure of maternal condition, and the measure of paternal resources could not be assessed for all fathers in the study.

\section{M ethods}

Subjects and measures

The study population consisted of all permanent inhabitants of a single $Y$ anomamö village on the U pper Orinoco R iver in southern Venezuela in July 1998 $(\mathrm{N}=148)$. A complete census of the village was taken, and the age and parents of each individual inhabitant recorded. The results were cross-checked with several informants, and particular care was made to ensure that informants understood the difference between biological and classificatory parents. Care was also taken to identify biological siblings, especially those with deceased or absent parents who might inadvertently be assigned different ID codes. Informants were young adult Y anomamö males who spoke Spanish.

A nthropometric and health data were collected from all children in the village between the ages of 5 and 15 over a period of 2 days ( 21 males and fifteen females; 
Table 1. Variables examined in the study

\begin{tabular}{|c|c|}
\hline Variables & Description \\
\hline \multicolumn{2}{|l|}{ D ependent variables } \\
\hline Nutrition & Triceps skinfold thickness \\
\hline H ealth & Skin ectoparasite load (Tunga penetrans) \\
\hline Family size & $\begin{array}{l}\text { N umber of father's children + number of children of } \\
\text { sons-in-law performing bride service for the father } \\
\text { (i.e. children of resident daughters) }\end{array}$ \\
\hline \multicolumn{2}{|l|}{ Independent variables } \\
\hline Paternal access to food resources & $\begin{array}{l}\text { Garden productivity for each head-of-household (all } \\
\text { male) }\end{array}$ \\
\hline Child's access to parental resources & Orphan status \\
\hline Sibling competitors & Number of full siblings \\
\hline Distribution of kin & $\begin{array}{l}\text { F gCON : average degree of relatedness to } \\
\text { consanguineal kin } \\
\text { F gALL: average degree of relatedness to all village } \\
\text { members }\end{array}$ \\
\hline A ge-biased investment & A ge of the mother's youngest offspring \\
\hline Child's access to paternal resources & $\begin{array}{l}\text { M other's status in polygynous households (i.e. junior } \\
\text { or senior wife by age) }\end{array}$ \\
\hline$M$ ating effort & N umber of father's wives \\
\hline Political resources & Lineage size \\
\hline Control variable & Child's age \\
\hline
\end{tabular}

'four males and one female were orphans). A ges of most of the children were obtained from a list of birthdays kept by the village schoolteacher. Children not on this list were assigned the median of all ages offered by informants for that particular child. Thus, if two informants claimed a child was 12 , while a third claimed she was 14 , the child was assigned an age of 12 .

Dependent variables: measures of nutrition and health

T wo indices of nutrition and health were measured for each child: triceps skinfold thickness and skin ectoparasite load (see Table 1 for a list of dependent and independent variables examined in this study; see Tables 2 and 3 for descriptive statistics of these variables). Triceps skinfold thickness is a measure of skin and adipose tissue, and is thus an index of nutritional status. Triceps skinfold thickness has a reasonably strong correlation with body density (and thus with body fat). F or example, in a careful study of the correlation between various skinfold thicknesses and body density in young adult males (Lohman, 1981), the zero-order correlation of triceps skinfold thickness and body density was 0.78 , compared with 0.85 for abdominal skinfold thickness and 0.51 for chest skinfold thickness; the best multi-site model developed in the study had a correlation coefficient of 0.90 with body density. 
Table 2. Descriptive statistics of all variables assessed for village boys

$N$ M in. M ax. M ean SD

A ge (years)

Triceps skinfold thickness $(\mathrm{mm})$

$\begin{array}{lllll}21 & 5.00 & 15.00 & 9 \cdot 10 & 3.14\end{array}$

Skin ectoparasite load (index)

$\begin{array}{lllll}21 & 3.50 & 8.00 & 5.26 & 1.32\end{array}$

Paternal investment (index)

$\begin{array}{llllll}21 & 0.00 & 2.00 & 0.33 & 0.66\end{array}$

A ge of mother's youngest child (years)

$\begin{array}{lllll}17 & 2.00 & 4.00 & 3.00 & 0.87\end{array}$

N o. of mother's offspring

$\begin{array}{lllll}21 & 0.42 & 9.00 & 5.37 & 3.45\end{array}$

$\mathrm{N}$ o. of father's offspring

$\begin{array}{lllll}21 & 1.00 & 7.00 & 4.14 & 1.71\end{array}$

$\mathrm{FgCON}$ (average degree of relatedness to consanguineal

$\begin{array}{lll}21 & 1.00 & 11.00\end{array}$

$6 \cdot 19 \quad 2 \cdot 71$

relatives in the village)

$\begin{array}{lllll}21 & 0.13 & 0.43 & 0.26 & 0.095\end{array}$

F gALL (average degree of relatedness of all village members) $\begin{array}{llllll}21 & 0.02 & 0.08 & 0.044 & 0.019\end{array}$

Size of child's patrilineage

$\begin{array}{lllll}21 & 3.00 & 24.0 & 15.5 & 8.0\end{array}$

Table 3. Descriptive statistics of all variables assessed for village girls

\begin{tabular}{lrrrrr}
\hline & $N$ & M in. & M ax. & M ean & SD \\
\hline A ge (years) & 15 & 5.00 & 14.00 & 9.00 & 3.00 \\
Triceps skinfold thickness (mm) & 15 & 4.00 & 16.50 & $7 \cdot 60$ & 3.55 \\
Skin ectoparasite load (index) & 15 & 0.00 & 0.00 & 0.00 & 0.00 \\
Paternal investment (index) & 14 & 2.00 & 4.00 & 3.53 & 0.74 \\
A ge of mother's youngest child (years) & 15 & 0.42 & 14.00 & 5.54 & 4.34 \\
N o. of mother's offspring & 15 & 1.00 & 6.00 & 3.40 & 1.35 \\
N o. of father's offspring & 15 & 1.00 & 8.00 & 4.27 & 2.34 \\
F gCON (average degree of relatedness to consanguineal & 15 & 0.14 & 0.50 & 0.27 & 0.11 \\
relatives in the village) & & & & & \\
F gA L L (average degree of relatedness of all village members) & 15 & 0.01 & 0.07 & 0.043 & 0.021 \\
Size of child's patrilineage & 15 & 2.00 & 24.0 & 14.5 & 9.88
\end{tabular}

A similar study of male children found the zero-order correlation of triceps skinfold thickness with body density to range from 0.73 to 0.81 (Sarría et al., 1998). There is also evidence that the proportion of total body fat stored subcutaneously decreases as total body fat decreases (A llen et al., 1956; Durnin \& Womersely, 1974; Edwards et al., 1955, cited in Lohman, 1981), increasing the sensitivity of skinfold measurements to variation in nutrition. Skinfold thicknesses also fluctuate rapidly in response to changes in nutritional intake (e.g. M ascarenhas, Zemel \& Stalling, 1998), making them an appropriate index to track changes in distributions of parental care during periods of short-term food stress, as opposed to, for example, height-for-age, a measure that is more appropriate for assessing growth, an index of long-term parental investment (see, e.g., Sellen, 1999). Weight-for-age, weight-for-height and body mass 
index would have been useful measures of both short- and long-term nutritional status and were part of the original study design; unfortunately, the digital scale malfunctioned, preventing collection of these data.

Although food is distributed to children primarily by mothers among the $Y$ anomamö (Hames, 1992), the index of body fat cannot be used as a direct index of access to food because anthropometric status is also influenced by increased rates of nutrient utilization (as in many infectious diseases, e.g. diarrhoea), and/or impaired absorption or assimilation of, or access to, macro- and micro-nutrients (WH O, 1995). H owever, it is a reasonably good index of parental care. Children with infections who receive more parental care (for example, continued feeding and/or visits to the local mission infirmary) are likely to suffer fewer nutritional deficits than those who receive less care. For example, in a randomized, controlled study of young Peruvian children with acute diarrhoea, those who received continued oral feeding with a 'full strength' formula had significantly greater increases in skinfold thickness (and other nutritional measures) than those receiving only glucose-electrolyte solution intravenously (Brown et al., 1988). A mong the Y anomamö, parents typically feed bananas and/or plantains to their children when they have diarrhoea, though some reduce feeding, a common pattern in rural communities. Although the prevalence of infectious disease among children was not systematically investigated, it was suspected that few were currently burdened by diarrhoea. The water supply at the field site was excellent, and no complaints of diarrhoea were heard, although researchers were constantly asked to treat other minor ailments. Also, children with access to more food would regain body fat faster after a bout of diarrhoea than those with access to less food. Thus, an index of body fat is considered a reasonable composite index of access to both food and to parental care during illness.

Triceps skinfold thickness was obtained according to WHO guidelines (WHO, 1995). Specifically, the point of posterior aspect of the right upper arm midway between the lateral projection of the acromion process at the shoulder and the olecranon process of the ulna was determined to the nearest millimetre using a plastic tape-measure, and marked with a pen. The skinfold thickness was measured at this point over the triceps muscle using a pair of Slimglide skinfold calipers. Skinfold measurements typically have a non-normal distribution, so they were log-transformed prior to analysis. A Shapiro-Wilk test indicated that the resulting male and female distributions were not significantly different from a normal distribution.

Infections of sand fleas (Tunga penetrans) were endemic in the village, and the parasite often had to be removed daily. For children, removal frequently required the help of a parent. Based on an inspection of children's feet, by far the most common site of infection, children's ectoparasite loads were ranked as either low (0), moderate (1) or severe (2). Children's infections were ranked as severe if they had numerous open sores and disfigured toenails (where the egg mass is often laid), as moderate if they had few open sores but disfigured toenails, and as low if they had few or no obvious open sores and normal toenails.

All dependent variables above were obtained by a single researcher $(E H H)$. Unfortunately, an unexpected change in plans prevented a subset of children from being re-measured in order to assess the reliability of the measures. 
Independent variables: access to resources

With the exception of garden productivity, all independent variables used to test the study predictions were derived from the village genealogy (see Table 1). To assess access to food, every garden was visited with a single informant who identified the owner, and who ranked the size as small (1), medium (2) or large (3), and the soil quality as poor (1), medium (2) or good (3). A garden productivity score for each head-of-family (i.e. the father, $n=23$ ) was computed by multiplying the garden size by the soil quality, and summing over all gardens owned. At the time of the survey, one garden owner had just started a new garden. Because this garden was not yet productive, he was assigned the productivity score of his original garden.

Y anomamö society is organized by kinship, and patrilineages are the major political units. To test whether non-nuclear family variables accounted for any variance in the dependent measures, two additional categories of variables were derived from the village genealogy and used in post-hoc analyses: patrilineage size and average degree of relatedness.

The Yanomamö have a patrilineal form of social organization, and large patrilineages are generally able to out-compete smaller ones for access to resources (Chagnon, 1992). Patrilineage size is therefore a proxy measure of the political power of supra-family groupings in the village, and children - or particular categories of children - may benefit by belonging to a large patrilineage. All children might benefit if large patrilineages had higher per capita access to resources. A Iternatively, alliances between patrilineages involve the exchange of marriageable females, so older girls might benefit in view of the important role they play in inter-lineage politics.

Patrilineage size was calculated in the following manner: all village inhabitants (male and female) who were direct descendants of a deceased male (who himself had no living male ancestors in the village) were counted as belonging to a single patrilineage. This calculation of patrilineage size has some notable characteristics. Most important, patrilineage size was village specific. Individuals who had large numbers of patrilineal relatives living in other villages had a patrilineage size of ' 1 ' if none of these relatives lived at the study site. The most frequent examples of this were women who had married into village families, and sons-in-law performing bride service. In addition, because genealogical relationships between deceased individuals were not determined, individuals belonging to the same patrilineage might be assigned to different patrilineages. For example, if two individuals' fathers were deceased, then these individuals were counted as part of separate patrilineages, even if the fathers were brothers, i.e. even if these individuals were both descendants of the deceased grandfather and viewed themselves as belonging to the same patrilineage.

$\mathrm{K}$ inship is also a major organizing principle in $\mathrm{Y}$ anomamö society. Children with more relatives have more individuals interested in their welfare, but these children also have more competitors for limited resources. Children living with non-relatives or distant relatives have more mating opportunities than children living with close kin. Because $Y$ anomamö marriages are frequently arranged early and often involve exchanges of resources for brides (e.g. bride service), girls in particular may benefit from increased mating opportunities. Like patrilineage sizes, calculations of relatedness $(\mathrm{FgALL}, \mathrm{FgCON})$ are village specific. The degree of relatedness between two 
individuals is the probability that they share genes by descent; it is a unitless measure that is also referred to as W right's inbreeding coefficient (W right, 1922). Because it is a probability, it ranges from 0 to 1 . FgALL is the sum of Wright's inbreeding coefficient between an individual and all other living persons in the village to whom he/she is related, divided by the total number of living persons to whom he/she is compared, i.e. it is the individual's average relatedness to all living people, including non-related people. A high F gALL score implies that the individual is closely related to most people in the village whereas a low FgALL score implies that he or she is distantly or not related to most people in the village.

F gCON is the sum of W right's inbreeding coefficient between an individual and all the other living persons in the village to whom he/she is related, divided by the total number of the individual's actual genealogical relatives, i.e. the individual's average relatedness to just his or her living relatives. A high $\mathrm{FgCON}$ score means that most of an individual's relatives are close relatives, even if they are few in number. A low F gCON score means that most of an individual's relatives are distant relatives, even if they are many in number (for further discussion and examples, see Chagnon, 1974, 1979; Chagnon \& Bryant, 1984; W right, 1922).

\section{A nalytical procedures}

A II descriptive statistical analyses, linear regressions and multiple regressions were performed using SPSS 9.0 for W indows 95. Skinfold thickness was normalized by a log-transformation (as noted above), residual error was found to be normally distributed, and leverage statistics revealed no obvious problems with the regression analyses.

Triceps skinfold thickness has a non-linear relationship with age. If a reference population is available, the non-linear effects of age can be subtracted out by converting to $Z$-scores using the reference population. Because there was no reference population for triceps skinfold thickness for the Yanomamö, only the linear component of the relationship between age and triceps skinfold thickness was controlled for. However, there is little reason to believe that social variables like family size and wife status would be confounded with the non-linear component of the relationship between age and triceps skinfold thickness. With the obvious exception of 'age of the mother's youngest child', none of the social variables had a significant linear correlation with age, and there is no reason why they should be confounded with the non-linear component of a relationship that has much to do with physiological patterns of growth. Nonetheless, the inability to control for the non-linear component of the relationship between age and triceps skinfold thickness remains a limitation of this study.

\section{R esults}

N utritional stress

To the authors' knowledge, there is no appropriate triceps skinfold thickness reference population for the $Y$ anomamö. The triceps skinfold thicknesses of village children were therefore compared with those of a US population (F risancho, 1990). 


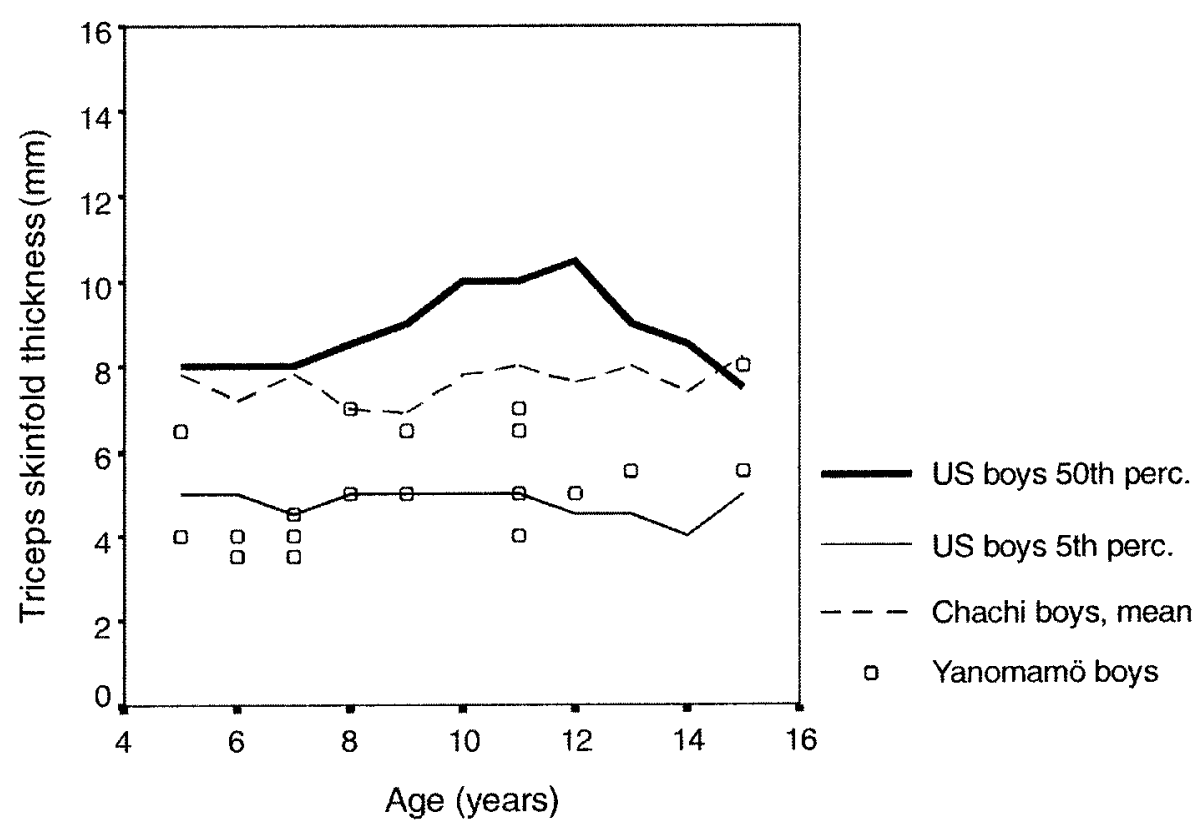

Fig. 1. M ale triceps skinfold thickness by age. Slightly fewer than half the village boys fall at or below the 5th percentile for U S males, a possible indicator of undernutrition. All village boys fall below the mean of the Chachi, another A mazonian horticultural group.

Forty-eight per cent of the boys (10/21) fell at or below the 5th percentile for the US male group, a possible indicator of undernutrition (WHO, 1995; see Fig. 1). In addition, all boys fell at or below the mean of the Chachi, an Ecuadorian horticultural group of A merindians (Eveleth \& Tanner, 1990), and 81\% (17/21) were more than one standard deviation below this mean.

The mean triceps skinfold thickness for all the boys was also compared with the mean for a group of $Y$ anomamö boys measured several years earlier in two other villages (this comparison group was also not a reference population). These earlier measurements were taken by one of the authors (Hames). The mean triceps skinfold thickness for the study site was significantly less than for the comparison group, even after controlling for differences in the age distribution $(p<0.001)$.

Village girls, particulary pre-adolescent girls, also appeared to be suffering from undernutrition, though perhaps not as much as the boys (see Fig. 2). Forty-seven per cent $(7 / 15)$ of the girls were at or below the 5 th percentile of U S girls. Eighty per cent $(12 / 15)$ of the girls fell below the Chachi mean, and $60 \%$ (9/15) fell one standard deviation below the mean.

H owever, unlike village boys, there was no significant difference between the mean skinfold thickness of village girls, and the mean thickness for a population of $Y$ anomamö girls measured several years earlier by Hames $(p=0.59)$. 


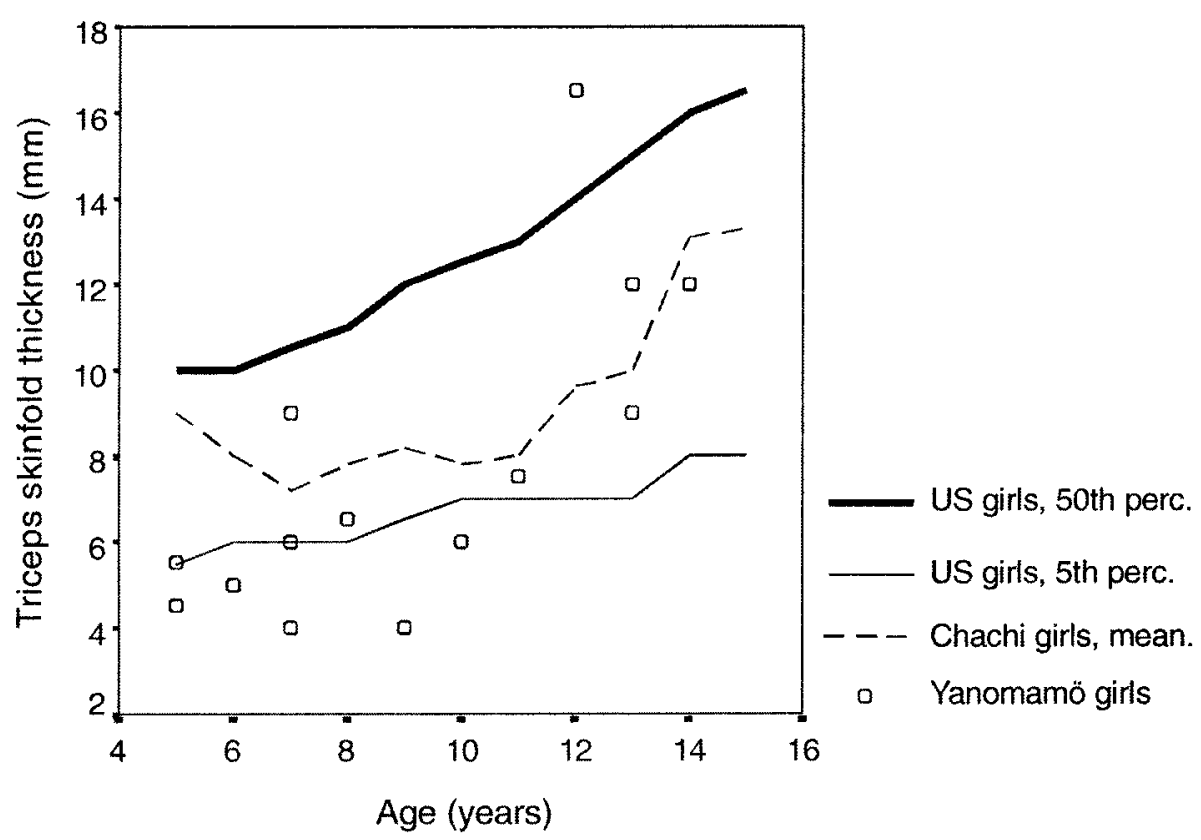

Fig. 2. F emale triceps skinfold thickness by age. One half the village girls fall at or below the 5th percentile for US girls, a possible indicator of undernutrition. Over three-quarters of the village girls fall below the mean of the Chachi. The outlier at $16.5 \mathrm{~mm}$ is the daughter of a high-status male.

Prediction 1: Resources and production of offspring

A ccess to resources should be positively correlated with family size, child nutrition and child health. This prediction was tested by comparing number of offspring with garden productivity for each family. Because resident sons-in-law were usually young males providing bride service to their fathers-in-law by working in their fathers-inlaws' gardens, and would therefore often not start their own gardens, the sons-inlaws' children were counted as part of their fathers-in-laws' families when assessing the relationship between garden size and family size. Five orphaned children were taken in by their grandfather, and were counted as part of his family. All garden owners were male heads-of-household.

Consistent with Prediction 1, a linear regression analysis found that family garden productivity accounted for $31 \%$ of the variance in family size $(n=23, r=0.56$, $p=0.006)$. F our of the seven family heads with no garden had alternative sources of 'income', either as practising shamans or school-teachers; two family heads were a brother of the headman and a local government official, respectively; one family head was an elderly man (age $\sim 60$ ). W hen families with no garden were omitted from the analysis, garden productivity accounted for $66 \%$ of the variance in family size $(n=16$, $r=0.81, p=0.00015$; see Fig. 3). 


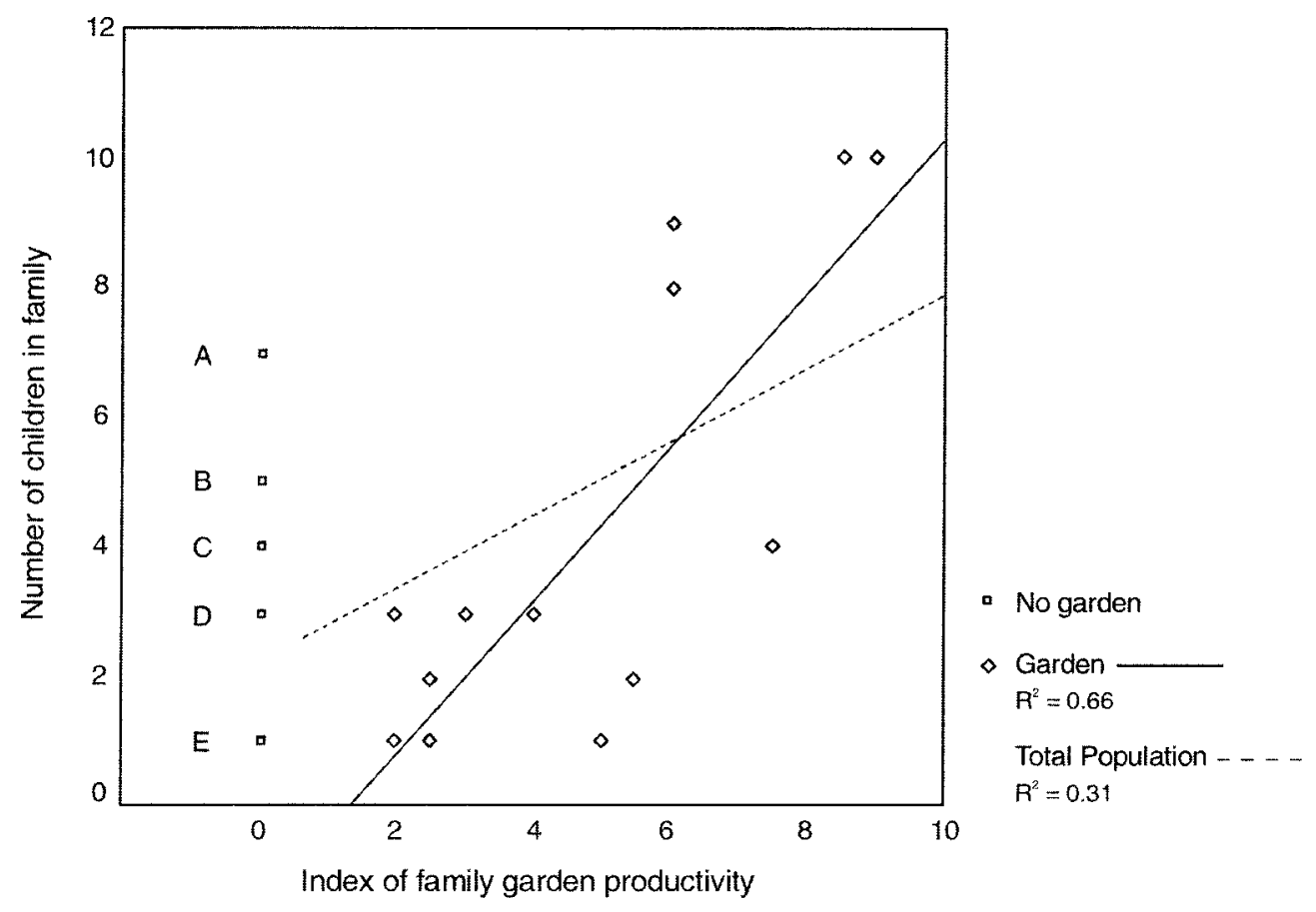

Fig. 3. Scatterplot of family garden productivity versus number of children. $R$ egression lines and adjusted $R^{2}$ values are included for the all families (dotted line) and for those families with gardens (solid line). Likely sources of 'income' for families without gardens are: (A) Shaman; (B) Shaman; (c) elderly member of a large lineage; (D) school-teacher, brother of a high-status male; (E) brother of a local official.

Tracking actual distributions of food in a community is a difficult task, and was well beyond the scope of this study. Unfortunately, it was not possible to develop a simple proxy for food income earned from shamanism or teaching. Since there was therefore no way to compare the resources of fathers with gardens to those fathers with these alternative sources of income, and because the sample size would have been too small if fathers without gardens were excluded from the study, garden productivity was not used in any subsequent analyses.

\section{Prediction 2: Q uantity versus quality}

Children with fewer sibling competitors should enjoy better health and nutrition than those with more. This prediction was tested by examining the relationship between health outcomes and number of siblings. No prediction or test for an 'optimal' number of children is offered. M ales and females have inherently different age-specific triceps skinfold thicknesses and were therefore compared separately in every test involving this variable.

Consistent with Prediction 2, the total number of father's offspring showed a significant negative correlation with male triceps skinfold thickness, controlling for the 
child's age $\left(R^{2}=0 \cdot 26, F_{\text {inc }}(1,14)=8 \cdot 00, p=0.013\right)$. Controlling for age, the total number of mother's offspring was not correlated with male triceps skinfold thickness. Controlling for both age and access to paternal resources (i.e. polygyny, see below), however, the number of mother's offspring was significantly negatively correlated with male triceps skinfold thickness $\left(R^{2}=0 \cdot 22, F_{\text {inc }}(1,13)=8 \cdot 67, p=0 \cdot 011\right)$.

The hypothesis was not upheld for females. Controlling for age, female triceps skinfold thickness was not significantly correlated with the total number of father's or mother's offspring. Controlling for access to paternal resources as well, female triceps skinfold thickness was still not significantly correlated with the number of mother's offspring, but it was positively correlated with number of father's offspring, contrary to the hypothesis $\left(R^{2}=0 \cdot 19, F_{\text {ind }}(1,11)=6 \cdot 66, p=0.026\right)$.

\section{Prediction 3: Paternal investment and child nutrition}

Prediction 3 was tested by comparing children's triceps skinfold thickness with their access to paternal investment. All else being equal, children with monogamously married mothers were presumed to have greater access to paternal investment than children whose mothers are married polygynously, as has been shown for some dimensions of paternal care in time-allocation studies conducted in other $Y$ anomamö villages (H ames, 1992, 1996). All else being equal, children of monogamous mothers were therefore expected to be better nourished and have better health. Because $Y$ anomamö mothers distribute food to children, children of senior mothers (assessed by age) were predicted to be better nourished than children of junior or divorced mothers. To test whether access to paternal resources correlated with child nutrition, each child with parents (seventeen males and fourteen females) was assigned a paternal investment score of 4 if his or her mother was married monogamously, a score of 3 if his or her mother was the senior wife by age in a polygynous marriage or the wife of a man with children by an ex-wife, and a score of 2 if his or her mother was the junior wife by age in a polygynous marriage or the divorced mother of a remarried man. Because polygynous men presumably had access to more resources than monogamous men, as was found in a previous study of other villages ( $\mathrm{H}$ ames, 1996), it is possible that these extra resources would 'mask' any negative impact from polygyny. Controlling for paternal access to resources would therefore increase the ability to detect any costs (or benefits) associated with polygyny. Unfortunately, it was not possible to control for paternal resources, as explained above in the section on garden productivity, reducing the sensitivity of this test. To control for the child's age and the number of mother's offspring, these variables were entered first in a multiple regression analysis, followed by the paternal investment score. In support of the prediction, male triceps skinfold thickness measurements had a significant positive correlation with access to paternal investment scores, despite not being able to control for male resources $\left(R^{2}=0 \cdot 24, F_{\text {inc }}(1,13)=9 \cdot 43, p=0.009\right)$. A fter controlling for age and number of full siblings, female children's triceps skinfold thickness showed no significant correlation with access to paternal investment, however, contrary to the prediction.

Paternal investment may also have had a positive impact on child health. Children's skin ectoparasite load was compared with their access to paternal 
investment. Both cases of severe infection were found in orphaned children (see Prediction 6 below). All three cases of moderate infection were found in children of junior or divorced mothers ( $p=0.017$, exact test). Thus, all cases of moderate or severe ectoparasite infection were found in children with limited or no access to paternal investment, consistent with the prediction.

\section{Prediction 4: $M$ ating versus parenting effort}

Controlling for the number of children, children in polygynous households should suffer poorer outcomes since fathers must provide sufficient mating effort to retain two wives. This prediction was tested by comparing children in monogamous and polygynous households. Controlling for the child's age and number of father's offspring (i.e. both full and half siblings), neither male nor female triceps skinfold thickness showed any significant correlation with the number of father's wives, contrary to the prediction. A gain, it was not possible to control for paternal resources (see the discussion section for more on the different costs of polygyny for men and women).

Prediction 5: Investment in older versus younger children

Because the study site had recently experienced short-term food stress, parents (mothers in particular) were predicted to have preferentially allocated investment to infants and younger children. Children with young siblings were therefore predicted to have poorer outcomes than other children.

The age of male children was entered into a multiple regression analysis, followed by the age of their mother's youngest child $(n=17)$. A s predicted, the latter variable was significantly positively correlated with triceps skinfold thickness $\left(R^{2}=0 \cdot 21\right.$, $\left.F_{\text {inc }}(1,14)=5 \cdot 70, p=0.032\right)$. A fter controlling for age, female children showed no significant correlation between the age of their mother's youngest child and triceps skinfold thickness, contrary to the prediction.

\section{Prediction 6: Inclusive fitness and health}

Parents should preferentially invest in biological offspring as opposed to stepchildren or other young dependents. This hypothesis was tested by examining the correlation between health outcomes and orphan status. There were five orphans in the child subject pool: four males and one female. A fter controlling for age, there was no significant association between orphan status and children's triceps skinfold thickness. There were, however, significant associations between orphan status and skin ectoparasite load. F orty per cent of the orphans (2/5) suffered severe infections, compared with none of the non-orphans. If orphans were included in the total child population, the rate of severe infection among children was only $5 \cdot 6 \%$, significantly less than the rate among orphans. H owever, because all orphans were being cared for by their maternal grandparents, these results do not support the hypothesis of kin-biased investment, but rather may indicate a constraint on the care-givers' time as opposed to food resources (see the discussion section). Unfortunately, the small 
number of orphans in the sample increases the probability that the different rates of infection, although statistically significant, are in fact an artefact of sampling error.

\section{Prediction 7: Differential investment by sex}

E vidence of differential investment in females and males was sought by comparing health outcomes by sex. Also, if different variables predicted female and male health outcomes, that would be evidence for differential investment. Direct tests of the Trivers-Willard hypothesis were not possible, however, because the pool of potential competitors for mates was much larger than the study site, because the relative wealth of parents in the village vis-à-vis parents in other villages with whom they were competing was unknown, and because there was no measure of maternal condition in any case.

W ith the exception of number of paternal offspring, none of the variables that predicted triceps skinfold thickness in males did so in females, suggesting that parents were investing food differently in each sex. However, the proportion and distribution of body fat stored subcutaneously appears to vary with both sex and age (Lohman, 1981). It is therefore also possible that females had a different physiological response to variation in nutrition and parental care, and that female triceps skinfold thickness was not a sensitive indicator of this variation. Further, detection of patterns in females may not have been possible due to the small size of the sample (a Type II error).

Several post-hoc analyses were performed in an attempt to discover whether any social variables were associated with female health and nutrition. Two variables were discovered that, together, were significantly associated with female triceps skinfold thickness: patrilineage size (positively correlated), and the average degree of relatedness to village inhabitants ( $\mathrm{Fg} L \mathrm{~L}$, negatively correlated). This multivariate model will be discussed in the next section. Skin ectoparasite load may also be associated with sex. All five cases of both moderate $(n=3)$ and severe $(n=2)$ penetrans infections were in males, a pattern that is not quite significant ( $p=0.068$, exact test).

\section{M ultivariate models}

Although age alone accounted for only $24 \%$ of the variance in male triceps skinfold thickness $(p=0.026$; Table 4, Model 1$)$, a multiple regression model incorporating age, the index of paternal investment discussed above, number of full sibling competitors, and age of the mother's youngest child accounted for $74 \%$ of the variance, and was highly significant ( $p=0.001$; see Table 4, M odel 2). A fter excluding age from the model, the three social variables still accounted for $66 \%$ of the variance $(F(3,13)=11 \cdot 1, p=0.001)$. $F$ urthermore, these three variables were nearly orthogonal, each having a tolerance of 0.95 or greater. Tolerance is the proportion of variance in each independent variable not accounted for by other independent variables in the model, i.e. virtually none of the variance in each of the three independent variables was accounted for by the other two. If a more comprehensive measure of 'mouths to feed', FgCON (average degree of relatedness to consanguineal relatives), was substituted for number of sibling competitors (while still excluding age), $74 \%$ of the 
variance could be explained ( $p<0.001$; see Table 4, M odel 3$)$. Since relatedness decreases exponentially with each genealogical remove, close relatives like full and half siblings contribute heavily to $\mathrm{FgCON}$ : individuals with many close relatives will have higher $\mathrm{FgCON}$ values than those with many distant relatives. Tolerance remained equally high, i.e. greater than 0.96 for each variable.

For females, age alone accounted for $45 \%$ of the variance $(p=0.003$; Table 3 , Model 4), whereas a multiple regression model incorporating age, patrilineage size and average degree of relatedness to village inhabitants (F gA L L) accounted for $71 \%$ of the variance in female triceps skinfold thickness $(p=0.008$; see Table 3, M odel 5 ). These three variables were not orthogonal. Although neither patrilineage size nor F gA LL was correlated with female age, they were correlated to each other, and the tolerance of each was $0 \cdot 23$. A s noted above, however, both were required in the model to achieve significance. $\mathrm{N}$ either of these variables correlated with male triceps skinfold thickness, either singly or in concert.

\section{D iscussion}

This study employed four sets of data: a village genealogy, children's triceps skinfold thickness (a measure of access to food resources and parental care), children's degree of infection by sand fleas (a possible measure of access to grooming), and the size and soil quality of all gardens as reported by a resident informant. The study was conducted shortly after a reported period of food stress attributed to EI Niño, a report consistent with the low levels of subcutaneous fat observed in village children, especially boys, relative to other populations ( $F$ igs 1 and 2). Based on triceps skinfold measurements, food and care appear to have been distributed unequally to children, and several variables were identified that illuminate the patterns of distribution. The large adjusted effect sizes and very significant $p$-values for many of the supported predictions indicate that Type I errors are unlikely, even with the small sample sizes (G reen, 1991). However, given the small sample sizes, the probability of Type II errors remains high for each of the unsupported predictions.

Family gardens are the major source of food for most individuals, and, as expected, garden productivity was highly correlated with family size (Fig. 3). This correlation increased significantly when families pursuing alternative subsistence strategies (e.g. practising shamanism in exchange for food) were excluded from the analysis. Unfortunately, family garden productivity could not be used as a variable in subsequent analyses because there was no obvious way to compare garden and non-garden families' access to food, and eliminating non-garden families would have reduced the sample size to unacceptable levels. Still, a basic premise of life history theory - that parental resources should be converted into offspring - is supported by these data, as well as by data collected in other $Y$ anomamö villages (Hames, 1996). The degree to which garden size constrains family size cannot be assessed with the data presented here, however.

Parents of both sexes pay a price for large families. Parental investment theory predicts that parents should experience a trade-off between the quantity and quality of offspring, a trade-off experienced by village parents in the energy stores of their male children. Controlling for age, the number of paternal siblings was significantly 
negatively correlated with the triceps skinfold thickness of village boys; controlling for age and access to paternal resources, the number of maternal siblings was also significantly negatively correlated with male triceps skinfold thickness. N either of these associations held for females, however. In fact, after controlling for age and access to paternal resources, female triceps skinfold thickness was positively correlated with the number of paternal offspring, consistent with the positive correlation also found for patrilineage size.

In addition to family size, parental investment also had an important impact on the nutrition and health of village boys. For example, the proxy measure of access to paternal investment (i.e. having a junior versus a senior versus a monogamous mother) accounted for a significant fraction of the variance in male nutrition. Controlling for the number of mother's offspring, boys whose mothers had a co-wife had less subcutaneous fat than those whose mothers did not, and those whose mothers were junior wives had less still. Ideally, this analysis should also have controlled for paternal access to resources. However, polygynous men presumably had access to more resources than monogamous men, as was found in a previous study of other villages (Hames, 1996), so controlling for access to resources would only strengthen the relationship found here. Paternal investment had a positive impact on children's health as well. Excluding orphans, all children with notable levels of skin ectoparasites had mothers who were either junior mothers or divorced, although the low numbers of children in this category suggests that this result be viewed as tentative at best.

Interestingly, though mothers appeared to pay a price in offspring nutrition by marrying polygynously, men did not. Controlling for the number of father's offspring, number of wives had no significant correlation with either male or female triceps skinfold thickness. Thus, for example, a mother bearing a child by a man who had no other wives or children would have a better nourished child than a mother who bore a child by a man who had another wife, all else being equal. However, a man could have four children by one wife or four children by two wives, and the children would be equally well nourished. Although the number of father's children was negatively correlated with nutritional status, the number of wives was not. This result is consistent with models that view polygyny as a consequence of male choice, not female choice. Whether the negative associations between polygyny and the nutritional status of children is due to dilution of paternal investment (as hypothesized in this study), co-wife competition, the lower quality of mothers in polygynous marriages, or other reasons is an important question for future investigation. The apparent negative impact of polygyny on women also raises the possibility that female mating decisions are constrained by interests that favour higher status males.

$\mathrm{N}$ ew family members also imposed an additional cost. As has been found by others (e.g. Hawkes, O'Connell \& Blurton Jones, 1997), the presence of young children had a negative impact on the nutrition of their older (and in this case male) siblings. This is expected to be especially true during periods of short-term stress because younger children are less likely to survive without sustained parental investment.

The predictive power of family variables in the above analyses strongly implies that kinship figures importantly in the distribution of food and care to children. The 
association of family size with garden productivity, the importance of paternal investment, and the impact of the number of siblings, particularly young siblings, on the nutritional status of village boys all indicate that food and care was distributed to boys primarily within rather than between families.

Although the poor health status of orphans would seem to also indicate an important relationship between kinship and child health, this is not necessarily the case. All five orphans (from four recently deceased parents) were being cared for by their maternal grandparents (the orphans' mothers were siblings). The grandparents' garden productivity was commensurate with the large number of children in their care. Indeed, there was no association between triceps skinfold thickness and orphan status. Orphans did suffer dramatically higher rates of severe infection by sand fleas, however, a result that must be interpreted with caution due to the very small sample size (but which should not be dismissed either: the severe infections suffered by male orphans were extremely debilitating). Rates of infection should be a function of exposure to the parasites, susceptibility to infection and access to grooming. One attractive hypothesis is that whereas the grandparents were able to increase their food productivity in order to care for their orphaned grandchildren, they were unable to provide sufficient grooming. Time, not food, was the resource in short supply. U nfortunately, there is a potential problem with this idea. R emoving sand fleas takes only a minute, and children can be quite good at it when they have access to needles. O ne of the severely infected orphans was asked if he was able to remove the egg sacks from his feet with a needle, and he demonstrated that he was able to do so. It is possible that orphans did not have ready access to needles. It is also possible that removing sand fleas on a daily basis is not as easy as this brief experiment suggests. Other anthropologists who work in A mazonian societies regard sand flea removal as difficult, viewing it as a minor surgical procedure that can be difficult to master, especially for children who only have access to thorns ( $M$ agdalena H urtado, personal communication).

When an informant was asked why some children suffered so badly from sand fleas, he replied that they spent more time with the village dogs (and therefore had increased exposure to fleas). It is also possible that the afflicted boys did not have regular use of a hammock, an expensive item, and had to sleep on the ground. $\mathrm{N}$ evertheless, parents are constantly grooming their children, and some orphans may have suffered from a lack of parental investment. The poor health of some orphans requires further investigation.

F inally, the strong association between family variables and nutrition for boys but not for girls is possible evidence of differential investment by sex. N one of the variables that predicted triceps skinfold thickness in boys did so for girls. W ere girls doing better or worse? This is difficult to determine from the data, but it appears that girls, particularly adolescent girls, may have been getting slightly more food and care. Three girls but no boys fell above the mean for Chachi triceps skinfold thickness, and two of the three were adolescents. One adolescent girl was substantially above the US median for females, though no boys were above the US median for males, and only $60 \%$ of the girls as opposed to $81 \%$ of the boys were more than one standard deviation below the Chachi mean. A lso, although not quite a significant correlation, every child with either moderate or severe infections of skin ectoparasites was male. 
Still, there was no compelling evidence for superior, as opposed to different, investment in either sex, and it is possible that the differences found were due to physiological differences, not differences in parental investment. It is also possible that female nutritional variation was associated with the same variables as male nutrition, but it was not possible to detect these effects due to the small size of the sample.

Post-hoc analyses identified two variables that correlated with female nutrition, variables that illuminate the possible differential investment in females and males. Together, both patrilineage size and the average degree of relatedness to all village inhabitants accounted for a significant fraction of the variance in female triceps skinfold thickness above and beyond that accounted for by age alone. Patrilineage size was positively correlated (as was a similar variable 'number of paternal offspring'), whereas average degree of relatedness was negatively correlated. $\mathrm{N}$ either of these variables was correlated with male skinfold thickness. M arriage of females is an important factor in the formation of alliances among $Y$ anomamö patrilineages. The data presented here are intriguing, though circumstantial, evidence that large patrilineages may have been investing surplus food in marriageable females, or that families wishing to establish and maintain alliances with large patrilineages were providing extra food to their marriageable women. Females with more potential mates, that is, with fewer consanguineal relatives in the village, may have been receiving additional investment as well. ( $\mathrm{FgCON}$, average degree of relatedness to consanguineal relatives, was correlated with male but not female skinfold thickness. It is possible to have a large $\mathrm{FgCON}$ score even if one has few relatives, if those relatives are close rather than distant relatives. By contrast, it is impossible to have a large F gA LL score - a correlate of female nutrition - without being related to a substantial fraction of village inhabitants.)

The primary limitations of the present study are its cross-sectional nature, small sample sizes and indirect proxies for parental investment that may be confounded by other variables like infectious disease. The low sample sizes in particular limit the possibility of rejecting hypotheses. Desired sample size is a function of the desired alpha (typically 0.05), power (typically 0.80 ) and desired effect size (typically 'medium', i.e. $\mathrm{R}^{2}=0.13$, or 'large', i.e. $\mathrm{R}^{2}=0 \cdot 26$ ). Because the effect sizes in the best models are very large, even after adjusting for the number of independent variables (e.g. A dj. $R^{2}=0.74$ ), and the significance levels are well below the standard alpha of 0.05 (e.g. $p<0.001$ in some cases), the probability that the effects found are due to random error is low (Green, 1991). However, the study had little power to detect moderate or small effects, and the probability of Type II errors remains high. F urther, the small sample sizes also increase the probability that the data were 'overfitted', and that the results may not generalize well to other populations, or even to this population at future points in time.

Finally, although the models are based on the assumption that children are suffering due to a dilution of parental investment, either from large families, infants in the family or the presence of co-wives, this study did little to illuminate the possible causal mechanisms and family dynamics that would result in differential nutritional status. F or example, the negative impact of polygyny on boys may have been due to the direct effects of co-wife competition, as suggested by, for example, Strassmann 
(1997), rather than a dilution of paternal investment. A Iternative explanations for the effects found remain a real possibility.

\section{Conclusions}

Simple measures have revealed interesting patterns of food allocations to children in a village that had recently experienced food stress. F or boys, these patterns are largely accounted for by three social variables: number of siblings, age of the mother's youngest child, whether the mother has a co-wife, and, if so, whether the mother is the junior or senior wife, with the best model accounting for $74 \%$ of the variance in skinfold thickness. These results accord well with parental investment theory (and common sense). Parents experiencing resource stress face a trade-off between quantity and quality, and between investing in younger versus older offspring. In addition, boys with access to more paternal investment (i.e. those in monogamous households) are better nourished and have better health than those with less access. The impact of these trade-offs on the parents' inclusive fitness is not known.

Interestingly, these variables did not account for any of the variance in female nutrition. The association of female nutritional status with the size of her patrilineage and the number of non-relatives in the village (variables that accounted for $26 \%$ of the variance in female triceps skinfold thickness) suggests that lineage politics may play a role in female nutrition, although this suggestion is quite speculative.

The apparent lack of any relationship between orphan status and triceps skinfold thickness is also interesting, especially in light of the fact that orphans suffered very high rates of infections by skin fleas. There is no clear explanation for this high rate of infection, but given the large number of orphans being cared for by only two grandparents, time may have been the resource in short supply.

\section{Acknowledgments}

The authors thank $\mathrm{N}$ apoleon Chagnon for substantial assistance in organizing a productive field season, Dan Shaylor and other members of the $\mathrm{N}$ ew Tribes $\mathrm{M}$ ission for their help on numerous occasions, and their hosts for providing generous accommodation and sharing their lives with them. They also thank $M$. Borgerhoff M ulder, B. Hewlett, F. M arlowe, M. Hurtado, P. Walker and two anonymous reviewers for many helpful comments and suggestions.

\section{R eferences}

A LeXander, R. D. (1974) The evolution of social behavior. Ann. R ev. E col. System. 5, 325-383. A llen, T. H., Peng, M. T., Chan, K. B., et al. (1956) Prediction of total adiposity from skinfolds and the curvilinear relationship between external and internal adiposity. M etabolism 5, 346-353.

B ateman, A . J. (1948) Intra-sexual selection in Drosophila. Heredity 2, 349-368.

BeCKeR, G. S. (1981) A Treatise on the Family. Harvard University Press, Cambridge.

BetZig, L. L., Borgerhoff M ulder, M. \& Turke, P. (Eds) (1988) H uman Reproductive Behavior: A Darwinian Perspective. Cambridge U niversity Press, Cambridge. 
Betzig, L. L. \& Turke, P. W. (1986) Parental investment by sex on Ifaluk. Ethol. Sociobiol. 7, 29-37.

B LURTON J ONES, N . (1986) Bushman birth spacing: a test for optimal interbirth intervals. Ethol. Sociobiol. 7, 91-105.

BLURTON J ONES, N . (1989) The costs of children and the adaptive scheduling of births: Towards a sociobiological perspective on demography. In: Sociobiology of Sexual and Reproductive Strategies. Edited by A. Rasa, C. Vogel \& E. Voland. Chapman and Hall, N ew Y ork.

BLuRton J ONES, N. (1994) A reply to Dr Harpending. Am. J. phys. Anthrop. 93, 391-396.

BorgerhofF M ULDER, M. (1988) The relevance of the polygyny threshold model to humans. In: H uman M ating Patterns. Edited by C. G. N. M ascie-Taylor \& A. J. Boyce. Cambridge U niversity Press, Cambridge.

BORGERHOFF M ULDER, M . (1995) Bridewealth and its correlates: Quantifying changes over time. Curr. A nthrop. 36, 573-603.

BORGERHOFF M ULDER, M . (1998) Brothers and sisters: How sibling interactions affect optimal parental allocations. H um. Nature 9, 119-161.

Brown, K. H., G astanaduy, A. S., SaAvedra, J. M., et al. (1988) Effect of continued oral feeding on clinical and nutritional outcomes of acute diarrhea in children. J. Pediatr. 112, 191-200.

ChaGnON, N . A . (1974) Studying the Yanomamö. Holt, R inehart and Winston, N ew Y ork.

Chagnon, N. A . (1979) M ate competition, favoring close kin and village fissioning among the $\mathrm{Y}$ anomamo Indians. In: Evolutionary Biology and $\mathrm{H}$ uman Social Behavior: An Anthropological Perspective. Edited by N. A. Chagnon \& W. Irons. D uxbury Press, N orth Scituate, M A.

Chagnon, N. A. (1992) Y anomamö. Harcourt Brace, N ew Y ork.

Chagnon, N . A . \& Bryant, J.R. (1984) Kindemcom: The Fourth Style in the Study of Human K inship Relationships. Harry Guggenheim Foundation, New Y ork.

C HIBNIK, M. (1984) A cross-cultural examination of Chayanov's theory. Curr. A nthrop. 25, 335-340.

Chisholm, J. S. (1993) Death, hope, and sex: life-history theory and the development of reproductive strategies. Curr. Anthrop. 34, 1-24.

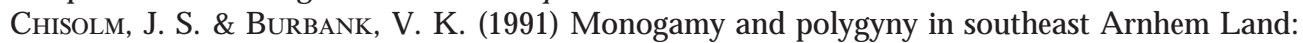
M ale coercion and female choice. Ethol. Sociobiol. 12, 291-313.

Clutton-Brock, T. H. (1991) The Evolution of Parental Care. Princeton U niversity Press, Princeton, $\mathrm{NJ}$.

CRONK, L. (1991) Preferential parental investment in daughters over sons. Hum. Nature 2, 387-417.

D ALY, M . \& W ILSON, M . (1984) A sociobiological analysis of human infanticide. In: Infanticide: Comparative and Evolutionary Perspectives. Edited by G. Hausfater \& S. B. H rdy. Aldine, $\mathrm{N}$ ew $\mathrm{Y}$ ork.

D ALY, M . \& W ILSON, M . (1988) H omicide. A ldine De Gruyter, N ew Y ork.

D Avies, N. B. (1989) Sexual conflict and the polygamy threshold. A nim. Behav. 38, 226-234.

D ICKEMANN, M . (1979) F emale infanticide, reproductive strategies, and social stratification: A preliminary model. In: Evolutionary Biology and Human Social Behavior. Edited by N. A. Chagnon \& W. Irons. Duxbury Press, N orth Scituate, M A.

D ICKEMANN, M . (1981) Paternal confidence and dowry competition: A biocultural analysis of purdah. In: $\mathrm{N}$ atural Selection and Social Behavior: R ecent R esearch and $\mathrm{N}$ ew Theory. Edited by R. D. Alexander \& D. W. Tinkle. Chiron Press, N ew Y ork.

D ownhower, J.F \& \& A RMitage, K . B. (1971) The yellow-bellied marmot and the evolution of polygamy. A m. Nat. 105, 355-370.

D RAPER, P. \& H ARPENDING, H. (1982) F ather absence and reproductive strategy. J . Anthrop. Res. 38, 255-273. 
D urnin, J . V. G . A . \& W omersely, J. (1974) Body fat assessed from total body density and its estimation from skinfold thickness: measurments on 481 men and women aged 16 to 72 years. Br. J. Nutr. 32, 77-97.

D urrenberger, P. (E D.) (1984) Chayanov, Peasants, and E conomic Anthropology. A cademic Press, N ew Y ork.

E dwards, D. A. W., H ammond, W. H., Healy, M. J.R., Tanner, J. M.\& W hitehouse, R. J. (1955) D esign and accuracy of calipers for measuring subcutaneous tissue thickness. Br. J. Nutr. 9, 133-143.

E veleth, P. B. \& TANneR, J. M. (1990) Worldwide Variation in H uman Growth. Cambridge University Press, Cambridge.

F RISANCHO, A. R. (1990) Anthropometric Standards for the Assessment of Growth and Nutritional Status. The University of M ichigan Press, Ann Arbor.

G Aulin, S. J . \& R obbins, C. J . (1991) Trivers-W illard effect in contemporary N orth A merican society. Am. J. phys. A nthrop. 85, 61-70.

G REEN, S. B. (1991) How many subjects does it take to do a regression analysis? M ultivariate Behav. Res. 26, 499-510.

H AGEN, E. H. (1996) Postpartum Depression as an Adaptation to Paternal and Kin Exploitation. Human Behavior and Evolution Society 8th A nnual Conference, N orthwestern University.

H AGEN, E. H. (1999) The functions of postpartum depression. Evol. hum. Behav. 20, 325-359.

H AIG, D. (1990) Brood reduction and optimal parental investment when offspring differ in quality. A m. Nat. 136, 550-556.

H AIG, D. (1993) Genetic conflicts in human pregnancy. Q. Rev. Biol. 68, 495-532.

H AMES, R. (1992) Variation in paternal care among the $Y$ anomamö. In: The Father's Role: Cultural and Evolutionary Perspectives. Edited by B. Hewlett. A ldine de Gruyter, Chicago.

H AMES, R. (1996) Costs and benefits of monogamy and polygyny for $Y$ anomamö women. Ethol. Sociobiol. 17, 181-199.

H ARPENDING, H. (1994) Infertility and forager demography. A m. J . phys. A nthrop. 93, 385-390.

H AWkes, K., O'Connell, J. F. \& Blurton Jones, N. G. (1997) Hadza women's time allocation, offspring provisioning, and the evolution of long postmenopausal life spans. Curr. A nthrop. 38, 551-577.

H EwLETt, B. S. (1991) Intimate Fathers: The Nature and Context of A ka Pygmy Paternal Infant Care. U niversity of $M$ ichigan Press, A nn A rbor.

H ILL, K.\& HurTado, A. M. (1996) Ache Life H istory: The Ecology and Demography of a Foraging People. A Idine De Gruyter, New Y ork.

H ILL, K . \& K APLAN, K . (1988) Tradeoffs in male and female reproductive strategies among the A che. In: Human Reproductive Behavior: A Darwinian Perspective. Edited by L. Betzig, M. Borgerhoff M ulder \& P. Turke. Cambridge U niversity Press, Cambridge.

H RDY, S. B. (1977) Infanticide as a primate reproductive strategy. A m. Sci. 65, 40-49.

H RDY, S. B. (1979) Infanticide among animals: A review, classification, and examination of the implications for the reproductive strategies of females. Ethol. Sociobiol 1, 13-40.

H RDY, S. B. (1992) Fitness tradeoffs in the history and evolution of delegated mothering with special reference to wet-nursing, abandonment, and infanticide. Ethol. Sociobiol. 13, 409-442.

I RoNS, W. (1983) Human female reproductive strategies. In: Social Behavior of Female Vertebrates. Edited by S. Wasser. A cademic Press, N ew Y ork.

J AMEs, W. H. (1987) The human sex ratio. I. A review of the literature. H um. Biol. 59, 721-752.

J OSEPHSON, S. C. (1993) Status, reproductive success, and marrying polygynously. Ethol. Sociobiol. 14, 391-396.

K elly, E. J. \& K ENNEDY, P. L. (1993) A dynamic state variable model of mate desertion in Cooper's hawks. Ecology 74, 351-356.

L ACK, D. (1947) The significance of clutch size. I bis 89, 302-352. 
L AMPERT, A . \& F RIEDMAN, A . (1992) Sex differences in vulnerability and maladjustment as a function of parental investment: An evolutionary approach. Social Biol. 39, 65-81.

L Essells, C. M . (1991) The evolution of life histories. In: B ehavioral Ecology. Edited by J. R. K rebs \& N. B. Davies. Blackwell, Oxford.

LoHmAn, T. G . (1981) Skinfolds and body density and their relation to body fatness: A review. H um. Biol. 53, 181-225.

M ACE, R. (1998) The coevolution of human fertility and wealth inheritance strategies. Phil. Trans. R. Soc. London B 353, 389-397.

M ANN, J. (1992) Nurturance or negligence: maternal psychology and behavioral preference among preterm twins. In: The Adapted M ind: Evolutionary Psychology and the Generation of Culture. Edited by J. H. Barkow, L. Cosmides \& J. Tooby. Oxford U niversity Press, Oxford.

M ARgulis, S. W., A ltmann, J. \& O Ber, C. (1993) Sex-biased lactational duration in a human population and its reproductive costs. Behav. E col. Sociobiol. 32, 41-45.

M ascarenhas, M. R., Zemel, B. \& Stallings, V. A. (1998) Nutritional assessment in pediatrics. Nutrition 14, 105-115.

M OCK, D. W . \& PARKER, G . A . (1986) A dvantages and disadvantages of egret and heron brood reduction. Evolution $\mathbf{4 0}, 459-470$.

Orians, G . H . (1969) On the evolution of mating systems in birds and mammals. A m. N at. 103, 589-603.

Pennington, R . \& H ARPending, H . (1988) Fitnesss and fertility among K alahari !K ung. A m. J. phys. Anthrop. 77, 303-319.

R ofF, D. A . (1992) The Evolution of L ife H istories: Theory and Analysis. Chapman and Hall, $\mathrm{N}$ ew Y ork.

San J OSE, C., Braza, F. \& Casanova, X. (1997) Reproductive status of mothers affects sex-biased parental investment in humans. Percept. M ot. Skills 85, 917-918.

SARría, A ., G ARCÍA-L LOP, L. A ., M ORENO, L. A ., et al. (1998) Skinfold thickness measurements are better predictors of body fat percentage than body mass index in male Spanish children and adolescents. Eur. J . clin. N utr. 52, 573-576.

Sellen, D. W. (1999) Polygyny and child growth in a traditional pastoral society. Hum. Nat. 10, 329-371.

SIEFF, D. F. (1990) Explaining biased sex ratios in human populations: A critique for recent studies. Curr. A nthrop. 31, 25-48.

Stearns, S. C. (1992) The Evolution of Life H istories. Oxford U niversity Press, Oxford.

Strassmann, B. I. (1997) Polygyny as a risk factor for child mortality among the Dogon. Curr. A nthrop. 38, 688-695.

Trivers, R. L. (1972) Parental investment and sexual selection. In: Sexual Selection and the Descent of M an. Edited by B. Campbell. A ldine, Chicago, IL.

Trivers, R. L. (1974) Parent-offspring conflict. Am. Z ool. 14, 249-264.

Trivers, R. L. (1985) Social Evolution. Benjamin/Cummings, M enlo Park, CA.

TRIVERS, R . L. \& W ILlaRd, D. E. (1973) N atural selection of parental ability to vary the sex ratio of offspring. Science $179,90-92$.

VERNER, J . \& W ILLSON, M. F. (1966) The influence of habitats on mating systems of North A merican passerine birds. E cology 47, 143-147.

VolAND, E. (1984) Human sex-ratio manipulation: Historical data from a German parish. J. hum. Evol. 13, 99-107.

WHO (1995) Physical Status: The Use and Interpretation of Anthropometry. Geneva, World $\mathrm{H}$ ealth Organization.

W ood, J. W. (1994) Dynamics of H uman R eproduction: Biology, Biometry, Demography. A Idine De G ruyter, N ew Y ork.

W RIGHT, S. (1922) Coefficients of inbreeding and relationship. Am. N at. 56, 330-338. 